\title{
Preparation and Exploration of Physical Properties of Calcium based Indian Origin Ayurvedic Medicine-Shankh Bhasma (Marine Drug) as Nanomaterials for its Applications
}

\author{
Sweta Sinha ${ }^{1}$, Rakesh Kr. Singh ${ }^{1 *}$, Nishant Kumar ${ }^{1}$, Subhash Pd. Singh ${ }^{2}$, Prabhat Kr. Dwivedi ${ }^{1}$ and Rekha Kumari ${ }^{3}$ \\ 1Aryabhatta Centre for Nano Science and Nanotechnology, School of Engineering and Technology, \\ Aryabhatta Knowledge University, Patna - 800001, Bihar, India; rakeshsinghpu@gmail.com \\ ${ }^{2}$ Department of Chemistry, AN College, Patna, Patliputra University, Patna - 800001, Bihar, India \\ ${ }^{3}$ Department of Zoology, AN College, Patna and Department of Education, Govt. of Bihar, \\ Patna - 800001, Bihar, India
}

\begin{abstract}
The objective of the present research is to explore the Physical properties of a marine origin of Indian Ayurvedic medicine (Shankh Bhasma) as nanomaterials for its applications. Shankh Bhasma has been prepared by using the method as mentioned in Ayurvedic text which includes aloe-vera and buttermilk as ingredient. The preparation method was ecofriendly and hazardous chemicals are not used or emitted during preparation. The bhasma are characterized by the modern scientific techniques. X-ray diffraction measurement and Scanning electron microsccopy analysis showed that Bhasma exists as agglomerated nano crystalline materials. Fourier transform infrared spectroscopy measurement reveals the bond stretching during the incineration process and found peaks of carboxylic group, calcium carbonate and calcium hydroxide. The photoluminescence measurement shows a broad spectrum in UV region and one prominent emission peak in the visible region at $405 \mathrm{~nm}$. The prepared shankh bhasma was examined on $E$. coli and found to have no effect. In present research, physical property measurement of shankh bhasma using state of the art techniques of $21^{\text {st }}$ century not only support a foundation for the development of low cost ayurvedic natural marine based materials as nanomedicne but also used in other sectors of science and technology.
\end{abstract}

Keywords: Ayurveda, Marine, Nanomaterials, Physical Properties, Shankh Bhasma

\section{Introduction}

The word "Bhasma" in Ayurveda stands for holy ash, which indicates superfine nanocrystalline powder. The word Ayurveda stands as a knowledge system for long life and considered as a medicinal portion obtained from nature, capable of human life simulation. In Bhasmikaran process minerals, metals and marine products are transformed into tiny size particles using herbs, fruit juice as an ingredient with quantum vibration of sound and together with heat treatment. These processes produce superfine powder, called holy ash as nanomaterial ${ }^{1-3}$. The nanomaterials represent the crystalline size ranging between $1 \mathrm{~nm}-100 \mathrm{~nm}^{4,5}$. The nanomaterials have found different properties as compared to bulk size materials. Generally, at the nanoscale surface structure causes discrete energy levels that yield drastic properties as compared to bulk size materials. Natural resources and marine based materials like conches have been used by traditional ayurvedic practitioners for a long time ago $^{5}$. In Rasashrashtra shankh bhasma is mentioned in the category of Sudhaverga. Bhasmas are found to be more efficacious than any other healing system due to superfine small particles and can show their efficacy at the molecular level, biocompatibility as compared to any chemically produced nanoparticles ${ }^{6}$. The metals are combined

\section{${ }^{*}$ Author for correspondence}


with herbs which help in assimilation and delivery of the ingredients in to human body ${ }^{7}$. Shankh Bhasma is an Ayurvedic Bhasma of the category Sudhaavarga. In Ayurveda science calcium containing dravyas (Sudhavarga), ie. Shankha, Shukti, Kapardika, pravala, Godanti, Khatika etc were incorporated in later period. But the knowledge of Indian origin medicine under this group is available since Vedic period ${ }^{8}$. These drugs mainly contain calcium carbonate. Shankha as a shell is very hard and dense structure and is commonly prepared and is mentioned in several Ayurvedic literatures. In the present research crystal structure of shankh bhasma was measured using X-ray diffractometer, scanning electron microscopy and found nanocrystalline. This is one of the reason, why seashell $\left(\mathrm{CaCO}_{3}\right)$ are hard materials as compared to other Ca based materials. Shankh Bhasma derived from conch shell is an Ayurvedic formulation popularly used for the treatment of dyspepsia and indigestion ${ }^{9}$.

Classically, Shankha Bhasma is alkaline in nature and causes significant reduction in ulcer index in both indomethacin and cold resistant models ${ }^{9}$. It is used for indigestion, flatulence, abdominal pain, vomiting belching, diarrhoea, belching and gastritis. The one of the objective of this research is to evaluate and explore the physical properties of shankh bhasma e.g. superfine structure, functional group, interaction nature among particles, surface morphology, and electronic structure using modern scientific tools of $21^{\text {st }}$ century. The modern scientific tools include- X-Ray Diffraction (XRD), Fourier Transform Infrared Spectroscopy (FTIR), Scanning Electron Microscopy (SEM) and Photoluminescence spectroscopy (PL). Calcinations is important process for size reduction and used to obtain percentage purity of bhasma materials. Therefore thermal analysis treatment using TGA-DTA like modern scientific equipments was also reported in this present work. Also, antimicrobial studies were reported on $E$. coli bacteria.

\section{Material and Method}

\subsection{Raw Materials}

The conch shells were collected from Bodh Gaya market of Gaya-Bihar. The juice of aloevera and buttermilk was used for decoction. The main purpose of using aloe vera and buttermilk were to prepare the formulation in the alkaline medium for better action and easily absorbed in the body as nanomedicine. The Shankh bhasma prepared using aloe vera as ingredient is denoted as SBA, while Shankha bhasma prepare using buttermilk is denoted as SBB.

\subsection{Nutrient Agar Media (NAM)}

NAM media is a complex media containing nutrients including extracts from yeasts, meat, or plants, or digests of proteins and other sources.

\subsection{Micro-organisms}

Gram negative bacteria, Escherichia Coli was used for microbial test. It is the most common inhabitant of lower intestine of warm blooded animals. It is chemoheterotroph that required carbon as a source of energy in medium.

\subsection{Synthesis of Shankh Bhasma as Nano materials}

The procedure for synthesis is shown in Figure 1. The method of synthesis is followed aa per the literature review $^{10}$. Bhasmikaran or Calcination technique was used to make bhasma in naometric size. Finally calcined form of calcium oxides are formed as a bhasma and kept in air tight container at room temperature and the characterization using modern scientific techniques e.g. XRD, TGA-DTA, SEM, FTIR, PL. There are three major steps of Ayurvedic bhasma preparation which was followed, and are mentioned as follow:

1. Purification: Five conch shells (sample) of about 1.5 $\mathrm{kg}$ were crushed into small pieces and tied with cloth. Then these cloth packets were boiled in water and washed thoroughly with distilled water three times and this process is known as Shodhan.

2. Levigation: All crushed conch shells (sample) were ground using grinder to make it in powder form. 500 gm powder of coch shells was mixed with aloevera juice, which is represented as SBA (shankh bhasma preparation using Aloe vera). Another 500 gm powder was mixed with buttermilk, represented by SBB (shankh bhasma preparation using buttermilk) simultaneously to make their dough. The resultant the cakes of both doughs were air dried for 2 hours.

3. Calcination: Cakes of SBA and SBB were kept in electric muffle furnace at $700^{\circ} \mathrm{C}$ for 3.5 hours. Again cakes were mixed with aloevera juice and buttermilk and kept in electric muffle furnace at $700^{\circ} \mathrm{C}$. Thus this process was repeated three times at regular interval of 3 hours during bhasmikaran process. Finally bhasma was prepared as a superfine white colour powder. The preparation details of shankh bhasma is shown as schametic diagram in Figure 1. During preparation, multiple heating and quenching in liquid media causes reduction in size of the particles, which is known as ecofriendly produced nanomaterials. 


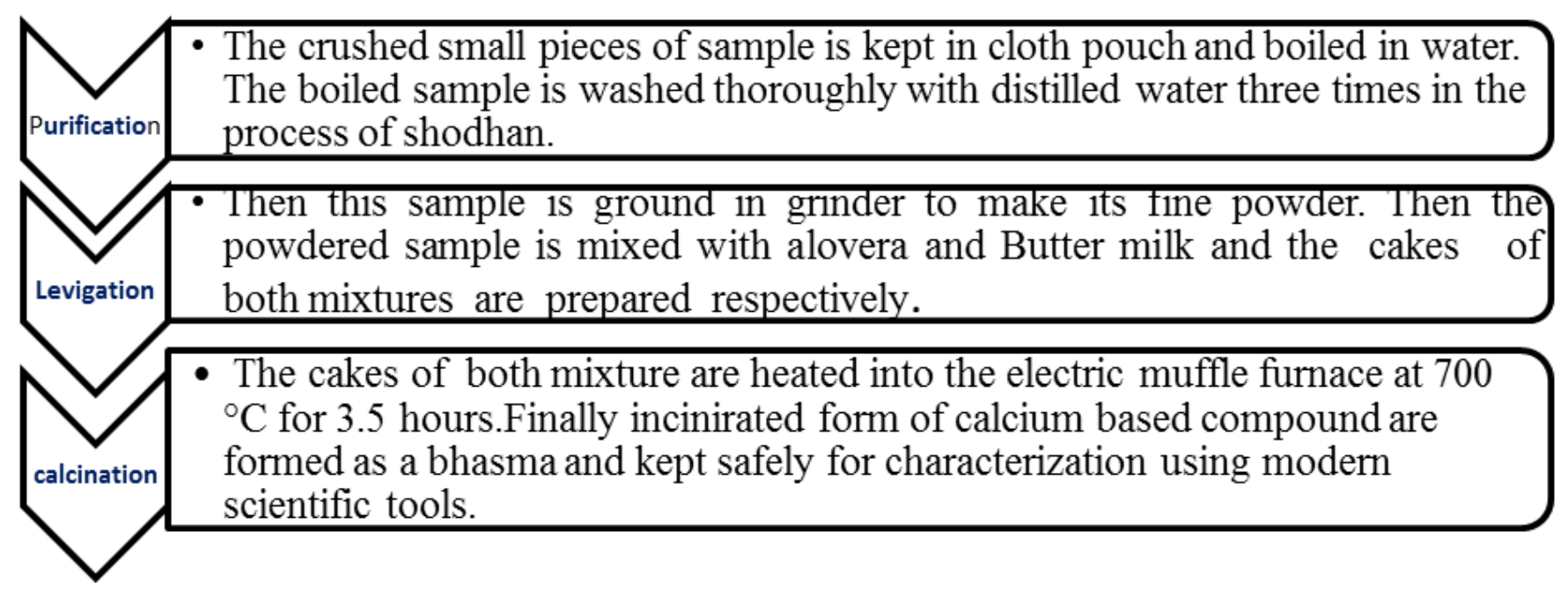

Figure 1. Synthesis procedure of Shankh Bhasmas (SBA and SBB).

\subsection{Preparation of Shankh Bhasma as Hand Washes}

Firstly the dirty hand was washed with normal distilled water and water was collected in test tube. Again the dirty hand was washed with Shankh Bhasma nanoparticles such as SBA and water was collected in test tube. The collected water was used for antimicrobial test in media. Few drops of water was taken from each tube and mixed with media in petri plates respectively. These plates were left overnight for incubation of temperature at $32^{\circ} \mathrm{C}$ and $70 \%$ humidity and microbial growth was checked. One of the main objective of this experiment was to obtain the hand wash effect as compared to other calcium based bhasma.

\section{Results and Discussion}

\subsection{Thermal Analysis}

Thermogravimetric Analysis (TGA) results of shankh bhasma prepared using aloe vera and buttermilk are shown in Figure $2(a-b)$. First significant weight loss of sample found to be at approximately $300-500{ }^{\circ} \mathrm{C}$ due to decomposition of moisture and organic compounds, whereas the most significant weight loss occurs between $600^{\circ} \mathrm{C}$ and below $700^{\circ} \mathrm{C}$, which is due to loss of $\mathrm{CO}_{2}$ from carbonate. The sample converted as $\mathrm{CaO}$ phase was similar to earlier reported work ${ }^{11}$. In addition, the DTA curve, attributed to an exothermic peak at around $674^{\circ} \mathrm{C}$, confirmed the decomposition to $\mathrm{Ca}(\mathrm{OH})_{2}$. The temperature of material should be above $725^{\circ} \mathrm{C}$ to form $\mathrm{CaO}$ completely which must be comparable from TGA curve, since there is no weight loss after $700^{\circ} \mathrm{C}$. This shows it is saturated after this temperature and the varied material should be hydroxide form. But on the other hand, the material SBB, the first significant drop is comparable with the SBA sample. But the major weight loss occurs in the range of after $680-750^{\circ} \mathrm{C}$ and there is also gradual shift in the exothermic peak in DTA curve to $743^{\circ} \mathrm{C}$ and this might be due to the formation of $\mathrm{CaO}$ or Calcite form of material present in the bhasma. The difference in thermal analysis measurement of SBA and SBB is due to interaction force between precursor powder of materials, which were prepared using Aloevera and buttermilk media. This thermal analysis measurement indicates that during synthesis these herbal based ingredients play an important role in the desired form as functional materials and prepared at a particular temperature. This thermal analysis measurement also highlights the necessity of ancient time ayurvedic physicians were used to prepared such materials at certain temperature range.

\subsection{Structural Measurement}

The crystal structure was analyzed using X-ray diffractometer for their structural parametric analysis. The result shows that the prepared materials SBA and SBB have peaks corresponding to $\mathrm{CaO}$ as well as $\mathrm{Ca}(\mathrm{OH})_{2}$ (Figure 3). The observation of $\mathrm{Ca}(\mathrm{OH})_{2}$ phases might be because of the sample exposed to humidity in the air ${ }^{12}$. The sharp peaks in the XRD pattern indicate the crystalline nature of $\mathrm{CaO}$ nanoparticles. The present study shows that shankh bhasma mainly contains $\mathrm{CaO}$ and $\mathrm{Ca}(\mathrm{OH})_{2}$ materials. Further crystallite size was evaluated using W-H plot and it was found that crystallite size for SBA is 73.71 $\mathrm{nm}$ and $86.78 \mathrm{~nm}$ for SSA respectively ${ }^{13}$ (Figures $4 \mathrm{a}$ and 
4b). Strain was found to be in agreement with crystallite size as it is found to decrease with increase in crystallite size, strain for SBA and SBB are 0.00116 to 0.00089 . Thus XRD measurement shows that marine origin shankh bhasma prepared using aloevera and buttermilk are nanocrystalline materials and depends on the ingredient used. One of the characteristics of nanomedicine is smaller the crystalline size, larger it remains in the body and better chance of being distributed in the target sites ${ }^{14}$.
At global level, commercially, various metal oxides are being produced, which are chemicals in nature, toxic and large energy is required for its preparation. But in this present research, calcium based nanomaterials are prepared using low cost ecofriendly approach in which no harmful gases are emitted. Such medicine could be reached to people due to its low price. Therefore this methodology of production of nanomedince may be an alternative method of production of calcium based materials at nanoscale.

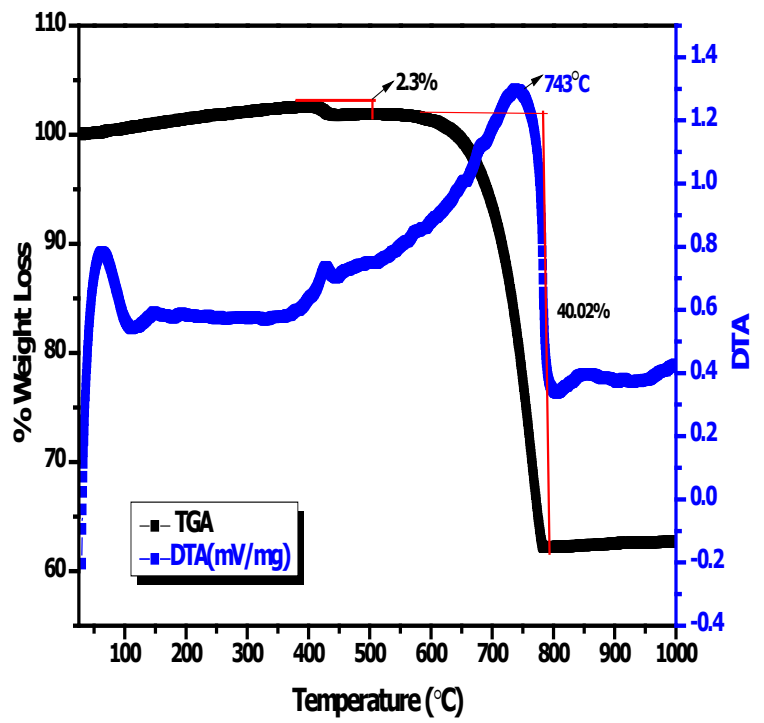

(b)

Figure 2. (a) TGA-DTA plot of SBA (b) TGA-DTA plot of SBB.

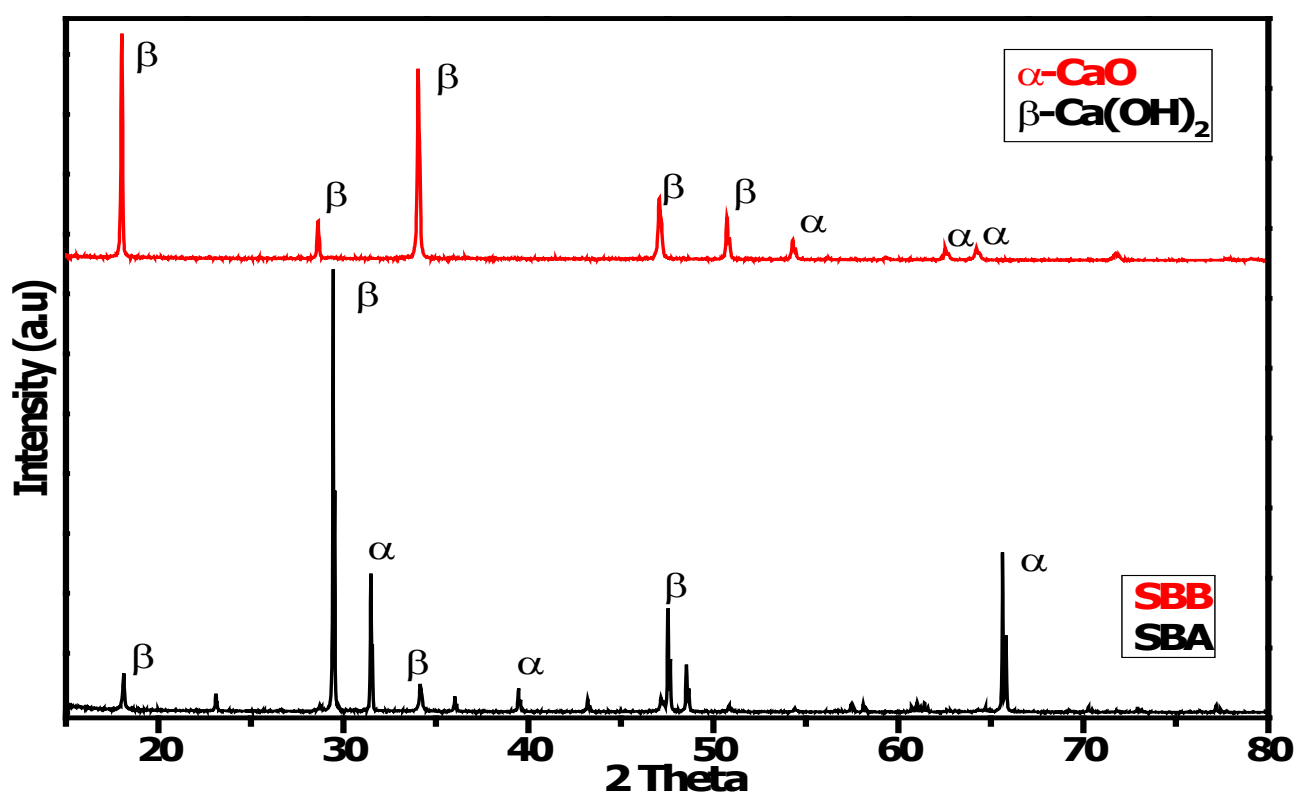

Figure 3. XRD pattern of SBA and SBB. 


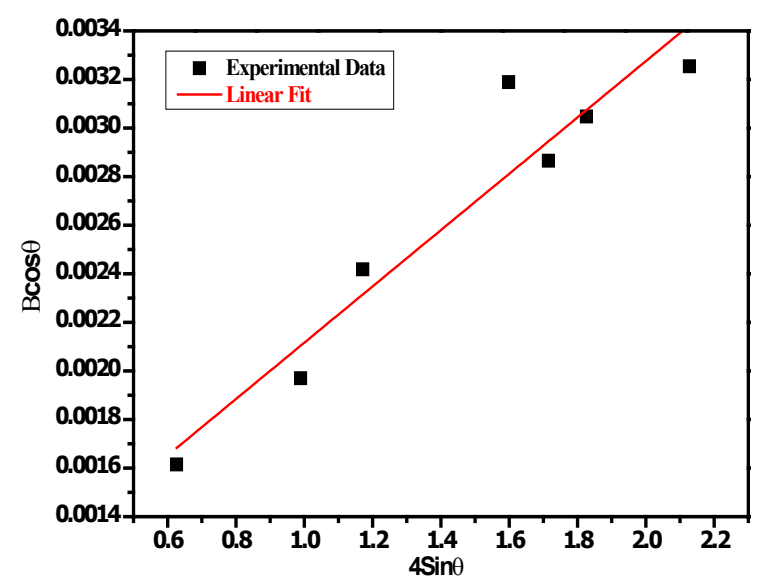

(a)

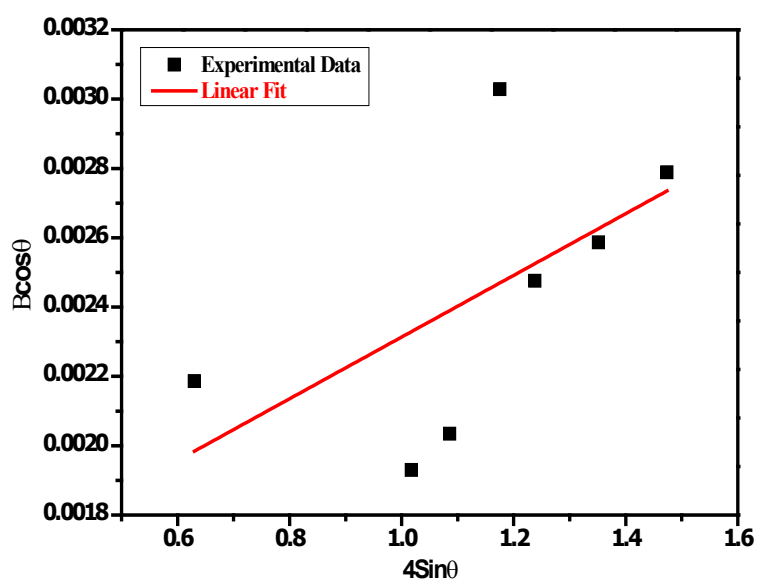

(b)

Figure 4. (a) W-H of SBA (b) W-H of SBB.

\subsection{Surface Morphology Measurement}

The morphology of the materials were studied using scanning electron microscope and are shown in Figure $5(a, b)$. The morphology of the nanoparticle was found to be oval and rod shaped with large agglomerated nanocrystalline particles. Multiple calcinations using aloevera and buttermilk and their interactional forces shows different agglomerated size particles. In the field

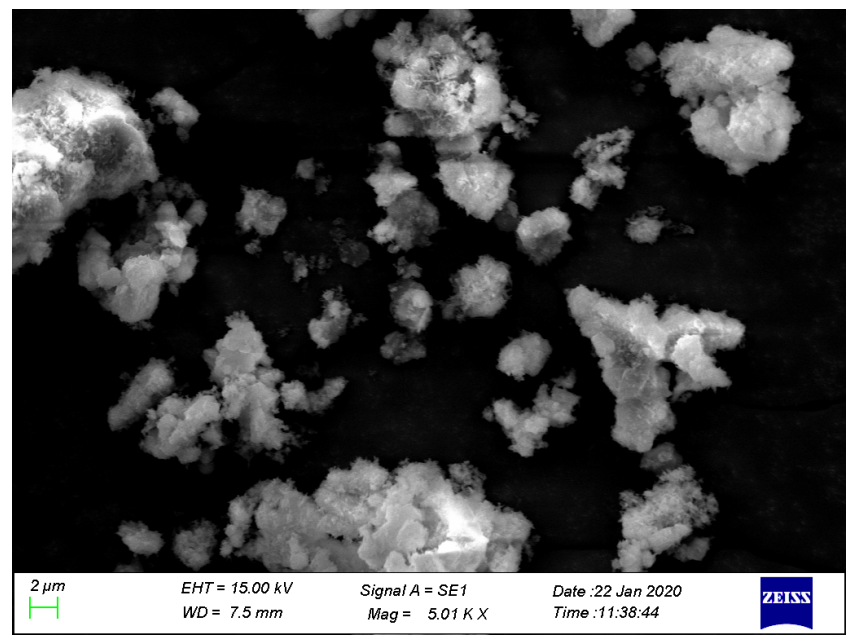

(a) of medicine, surface morphology dictates functional behaviors like bio distribution, cell internalization and cellular level. Hence, this ayurvedic bhasma is called targeted nanomedicne ${ }^{15,16}$. Agglomeration is a phenomenon at electromagnetic forces scale, in which crystals do not appear as single discrete unit but they appear in big clusters. Such agglomeration may be due to crystal-crystal interaction, and defects in crystal growth.

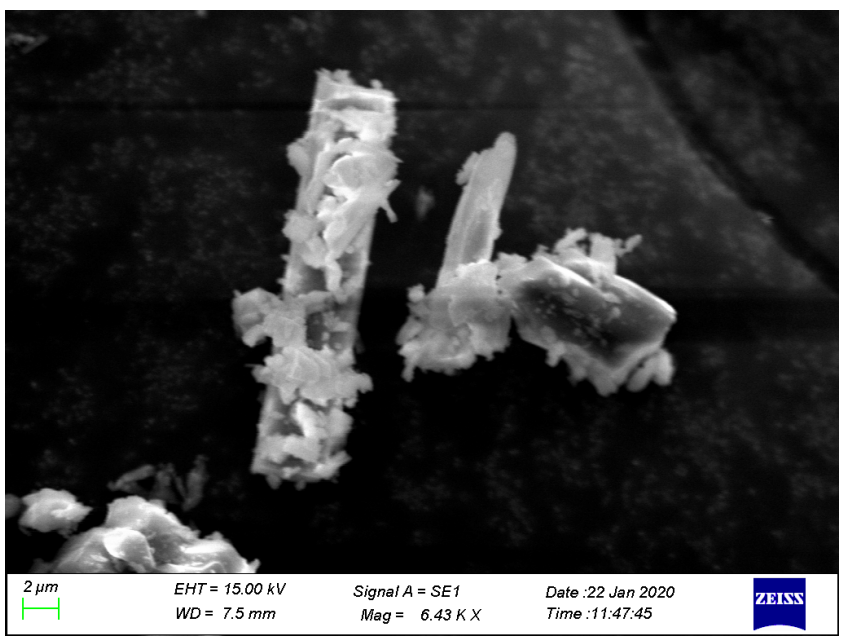

(b)

Figure 5. (a) SEM image of SBA (b) SEM images of SBB.

\subsection{Functional Group Measurement (FTIR Spectroscopy Measurement)}

The FTIR analyses materials functional group present in the prepared samples, and are shown in Figure 6 with details of functional group. The FTIR result of SBA showed broadband centering at $1415.52 \mathrm{~cm}^{-1}$ which is a characteristic of $\mathrm{C}-\mathrm{O}$ bond showing a bond between the oxygen atom of carbonate and calcium atom ${ }^{17}$. In 
addition, there were two sharp bands at $711.62 \mathrm{~cm}^{-1}$ and $875.54 \mathrm{~cm}^{-1}$ showing characteristics of C-O bond mainly calcite form which is relevant with our thermal analysis. Other broad band around $1500 \mathrm{~cm}^{-1}$ indicates the presence of $\mathrm{Ca}$ ion in the prepared material. The absorbtion band at $3641 \mathrm{~cm}^{-1}$ correspond to $\mathrm{OH}$ bond which might be the reason for formation of hydroxide ion. On the other hand, SBB nanoparticles showed mostly similar peaks as
SBB but a characteristic peak around $1074 \mathrm{~cm}^{-1}$ was found which are responsible for the formation of calcium oxide nanoparticles by carbonation process ${ }^{18}$. The presence of functional group depends on the type of ingredients used for preparation and in this present research aloe vera and buttermilk were used. Thus FTIR measuremebt highlights importance of Indian based traditional medicine, which are ecofriendly produced low cost $\mathrm{Ca}$ based materials of their origin from plant/natural ingredients.

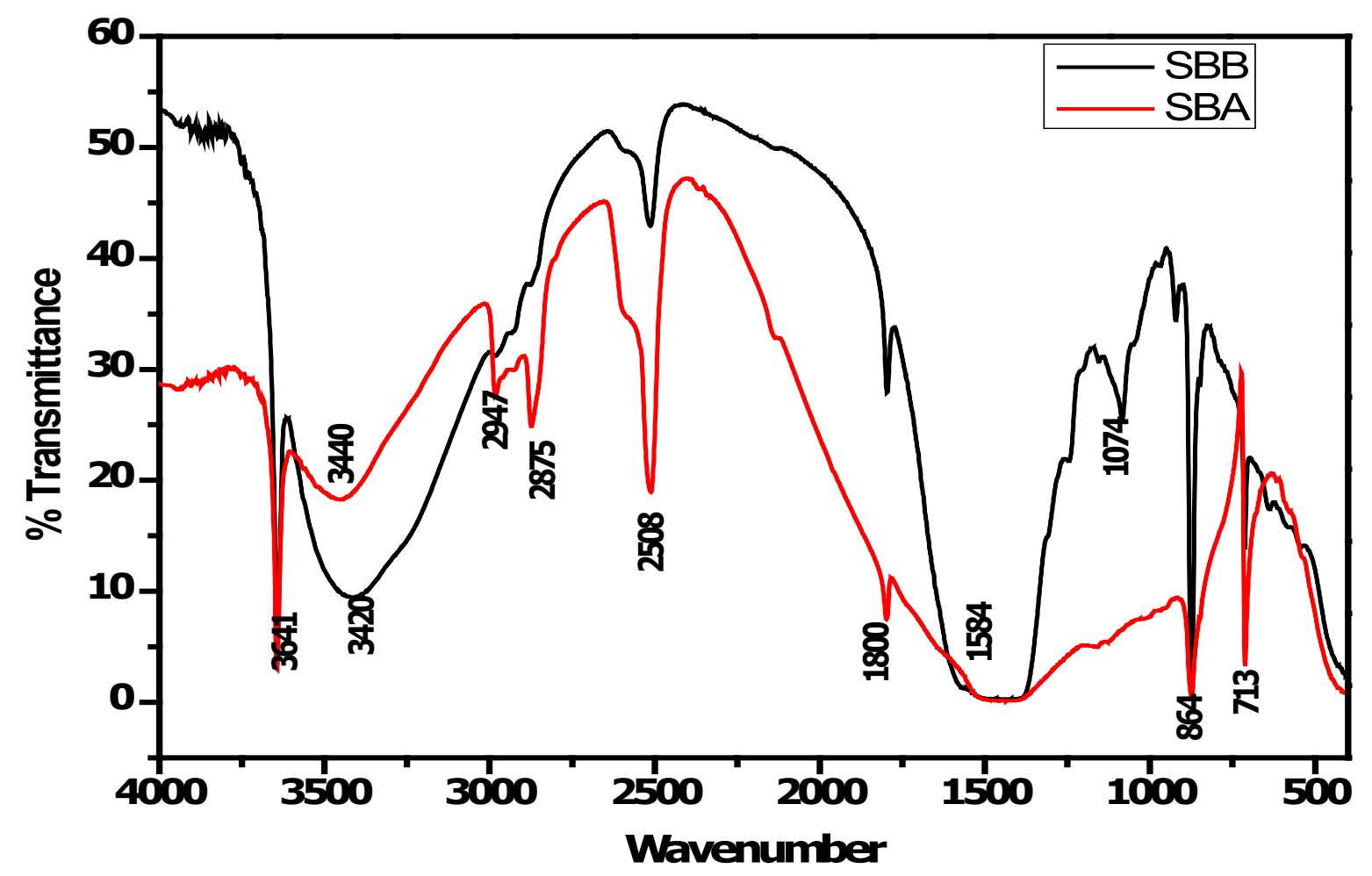

Figure 6. SFTIR spectra of Shankh Bhasma (SBA) and Shankh Bhasma (SBB).

\begin{tabular}{|c|c|}
\hline Peak position $\left(\mathbf{C m}^{-1} \mathbf{)}\right.$ & Assigned functional group \\
\hline 3641 & $\mathrm{OH}$ bond \\
\hline 3420 & $\mathrm{CaCO}_{3} / \mathrm{Ca}(\mathrm{OH})_{2}$ \\
\hline 2947 & Organic Matter \\
\hline 2875 & Organic Matter \\
\hline 1800 & $\mathrm{H}_{2} \mathrm{O}$ \\
\hline 1584 & $\mathrm{Ca} \mathrm{Region}$ \\
\hline 1074 & $\mathrm{CaO}$ \\
\hline 864 & Carbonate lon \\
\hline 713 & $\mathrm{C}-0$ \\
\hline
\end{tabular}

\subsection{Photoluminiscence Measurement}

Photoluminescence Spectroscopy is an important tool to study the optical property of materials. The excitations were recorded in the range up to $800 \mathrm{~nm}$. The emission spectrum in UV range having broad spectrum was obtained. The peak around $405 \mathrm{~nm}$ shows blue region confirmation and this might be originated from the recombination of free excitons due to exciton-exciton collision or might be due to intrinsic defects as oxygen and calcium interstitials. Since some groups also found such luminescence in metal oxides Like $\mathrm{ZnO}$ etc. ${ }^{19}$. Thus lumimiscience measurement shows that the prepared 
materials may be useful in other science and technology field. The only difference is that the materials are prepared using ecofriendly approach in which no harmful chemicals and gases are emitted. While other calcium based and metal oxide also shows such luminescence but are prepared using other physical and chemical method ${ }^{20}$, which are prepared using chemical method and its expensive production (Figure 7).

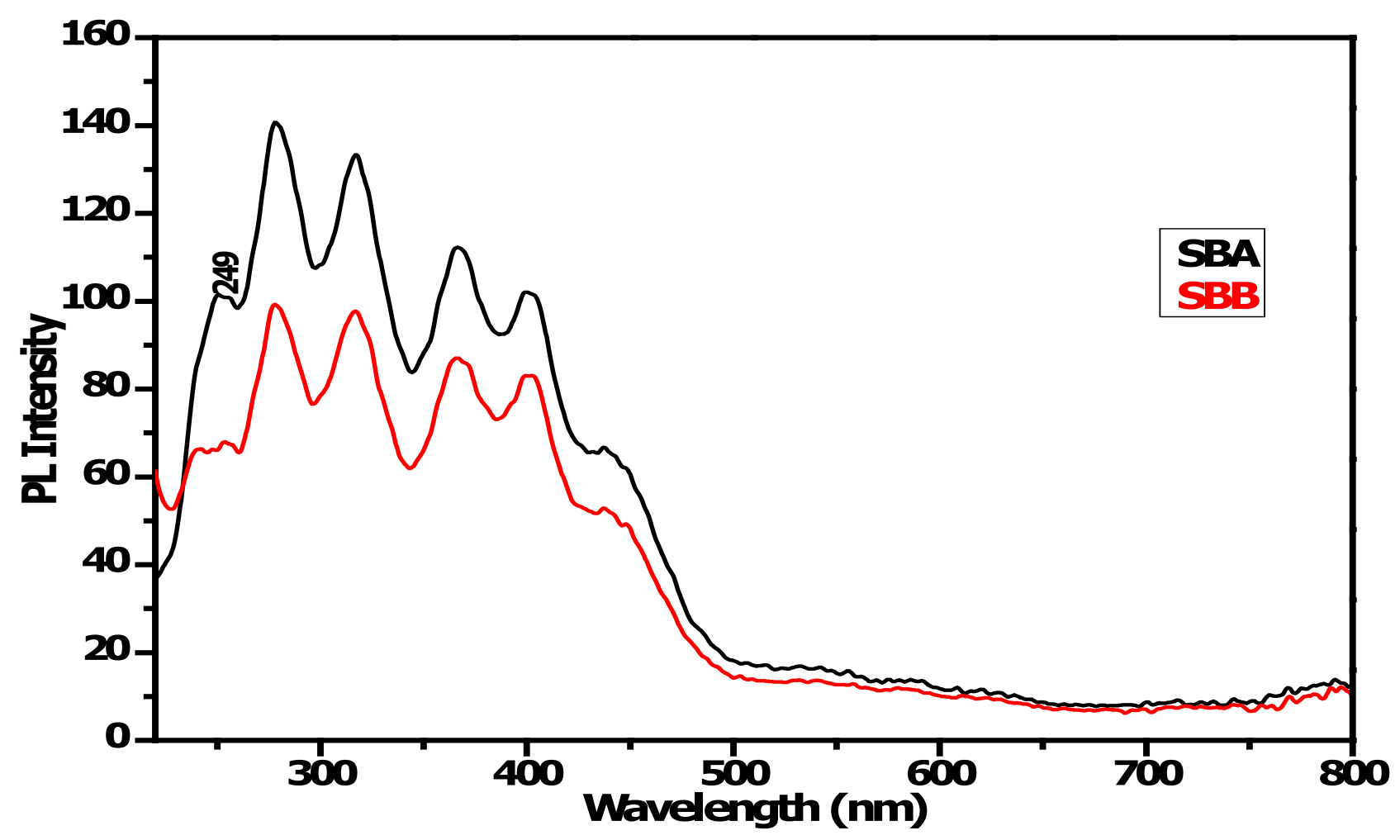

Figure 7. Photolminiscence spectra of SBA and SBB.

\section{Antimicrobial Property}

The effect of Shankh Bhasma nanoparticles (SSA) and SSB having average particle size $73.71 \mathrm{~nm}$ and $86.78 \mathrm{~nm}$ were checked on Escherichia coli, a gram negative bacteria. The zone of inhibition was not observed after incubation of 36 hrs as shown in Figure 8 (a), (b) and (c). Similar result was also reported by research group ${ }^{21}$. Same sample were treated as a hand wash and the result is shown in Figures 9 (a) and (b) respectively. There were microbial colonies observed in both distilled water treated sample and Shankh Bhasma as calcium based nanoparticles. This finding suggest that natural calcium based powder is not a potential agent for hand wash. While other $\mathrm{CaO}$ based shows in hand wash functional property (which were prepared using egg shell ${ }^{22}$. Thus present study shows calcium based materials prepared using marine based conch shells are not used in hand wash behaviour (Figures 10 and 11). Further study is required for difference in behaviour of calcium based nanomaterials and their applications from different sources with different crystalline size. In this research Shankh Bhasma as nonmaterial shows negative result treated with bacteria E.coli and also less antimicrobial effects in hand wash. However, size dependent behavior may result in some different property. Generally, the antimicrobial efficacy depends on materials employed for the preparation of the materials, crystalline size and surface morphology. Some Literature reviews also revealed that calcium based Bhasma shows very less antibacterial effect against $S$. aureus, $P$. aeruginosa and $E$. coli ${ }^{22}$. Thus, we can say that shankh bhasma containing enriched calcium has less antibacterial effects but may be effective in case of other microbes. This can be verified in future research work. 


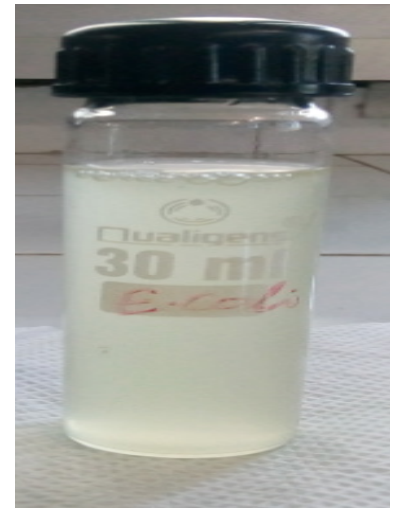

(a)

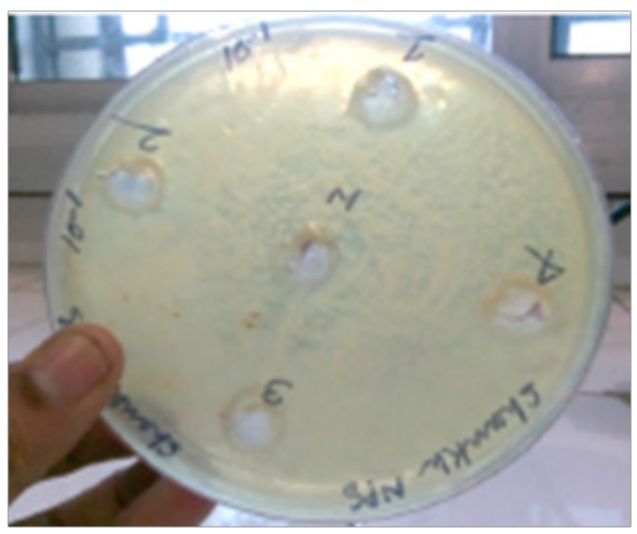

(b)

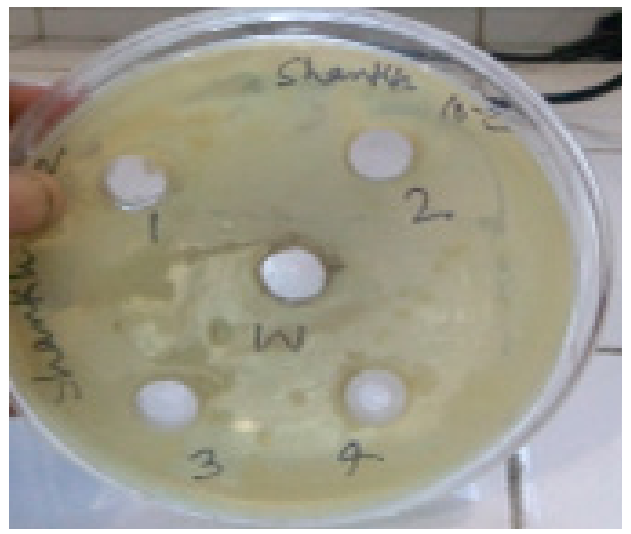

(c)

Figure 8. (a) Escherichia Coli subculture (b) Antimirobial activity for SBA (c) Antimicrobial activity of SBB NPs.

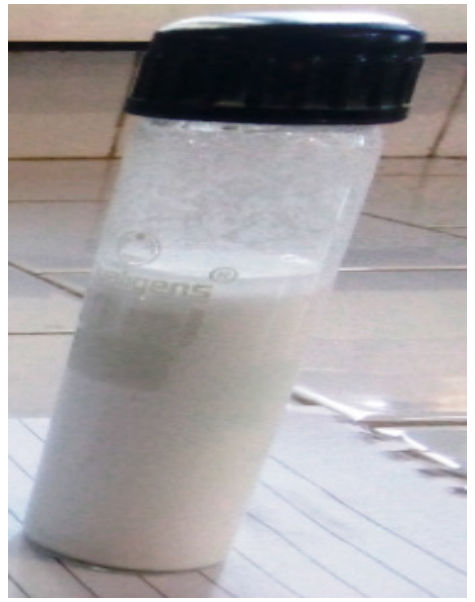

(a)

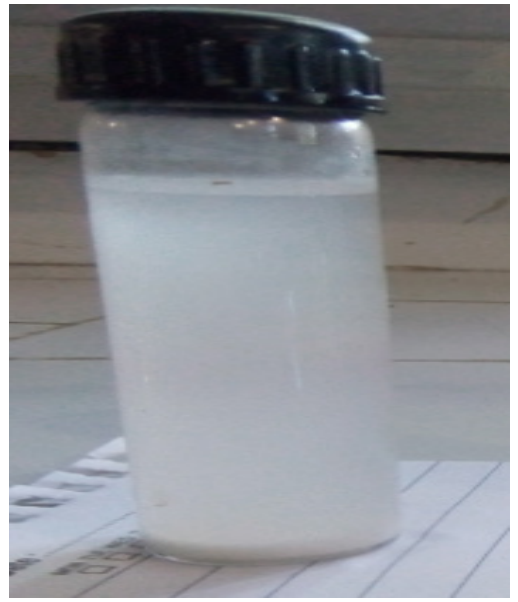

(b)

Figure 9. (a) SBA stock solution (b) SBA Hand - Wash water.

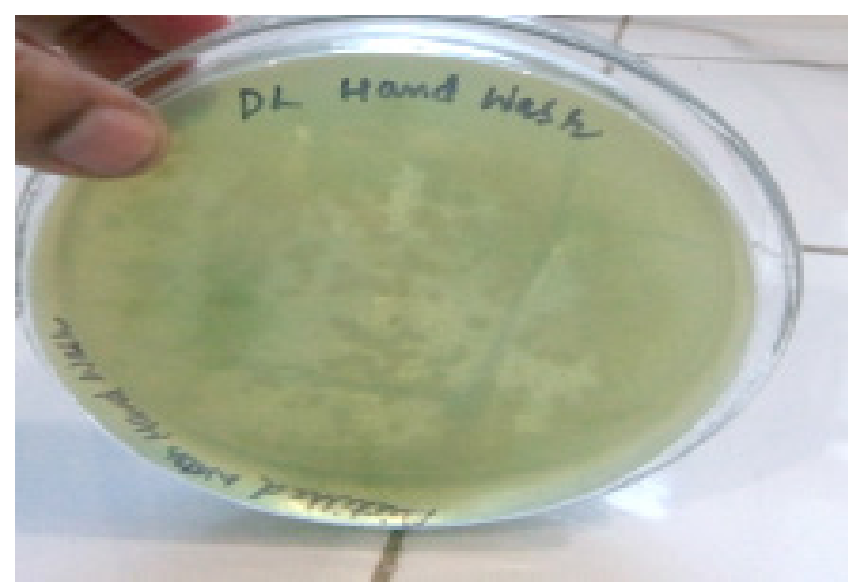

Figure 10. Distilled water as a Hand wash.

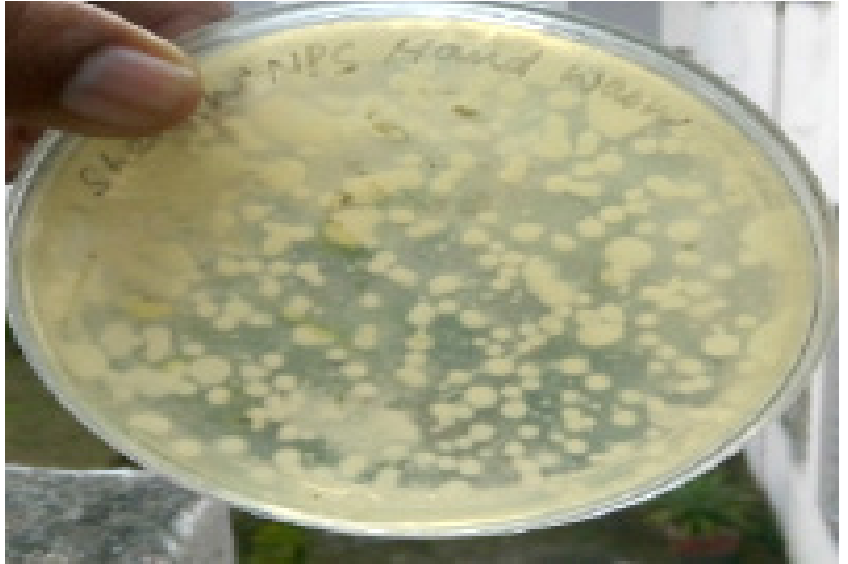

Figure 11. Shankh Bhasma Nps as a Hand wash. 
In nutshell, we can highlight the exploration of physical property measurement of shankh bhasma as nanomaterials support a foundation for the development of natural marine based ayurvedic bhasma, as evidence based nanomedicine not for various diseases but in other area of science and technology.

\section{Conclusions}

Marine origin Indian subcontinent based Shankh Bhasma as nanomaterials has been prepared by conch shell using aloe vera and buttermilk as ingredient. This shows that natural marine resources can be transformed into technological grade material at nanoscale using green approach. The preparation method was ecofriendly with hazardous chemicals free used or emitted during preparation. The bhasma are characterized by the modern scientific techniques. TGA-DTA measurement shows that major weight loss found in the temperature range 680-750 degree celcius and shift in the exothermic peak in DTA curve at 743 degree celcius and this may be due to formation of $\mathrm{CaO}$ and elimination of other elements like $\mathrm{S}, \mathrm{N}, \mathrm{C}$ and $\mathrm{P}$. Thermal analysis measurement highlights the ancient method of preparation at particular temperature. $\mathrm{X}$-ray diffractomter and Scanning Electron Microscopy measurement shows the particles sizes are less than $100 \mathrm{~nm}$ and may be treated as Indian origin ayurvedic natural nanomedicine. An FTIR measurement reveals the bond stretching during the incineration process and found peaks of carboxylic group, calcium carbonate and calcium hydrooxide. The photoluminescence measurement shows that broad spectrum in UV region and one prominent emission peak in visible region at $405 \mathrm{~nm}$. Efficacy was nor observed in Shankh bhasma treated on E. coli. The present research open a new window that low cost ayurvedic nanomedicine can be prepared using ecofriendly approach for benefit of huge population. The characteristics of this research also shows that such calcium based materials prepared using natural based techniques can be used in other area of science and technology due to its significant physical properties.

\section{Acknowledgments}

The following research has been efficiently conducted at Aryabhtta Center for Nanoscience \& Nanotechnology, Aryabhatta Knowledge University, Patna. Author expressed their gratitude to Aryabhatta Knowledge University, Patna and Dept. of Education, Govt. of Bihar for endorsing frontier research facility. Author are also thankful to
Magadh University, Bodh-Gaya for providing us necessary support for anti-microbial and Handwash test.

\section{References}

1. Vadnare G, Pathan A, Singhai, et al. Characterization of indigenous traditional medicine. Muktashukti Bhasma. Indian J Tradit Knowl. 2013; 12(2013):4838.

2. Chaudhary A. Ayurvedic Bhasma: Nanomedicine of ancient India, its global contemporary perspective. J Biomed Nanotechnol. 2011; 7(2011):68-9. https:// doi.org/10.1166/jbn.2011.1205. PMid:21485807

3. Palkhiwal S, Sonal R. Engineered nanoparticles: Revisiting safety concerns in light of ethno medicine. Ayu. 2014; 35(3). https://doi.org/10.4103/0974-85 20.153785. PMid:26664232. PMCid:PMC4649566

4. Nikalje AP. Nanotechnology and its applications in medicine. Med Chem. 2015; 5(2). https://doi. org/10.4172/2161-0444.1000247

5. Pal D, Sahu CK, Haldar A. Bhasma: The ancient Indian nanomedicine. J Adv Pharm Technol Res. 2014; 5(2014):4-12. https://doi.org/10.4103/22314040.126980. PMid:24696811. PMCid:PMC3960793

6. Sharma GRPPR. Revisiting the ancient claims of nanomedicine. BAOJ Nanotechnology. 2016; 2(2).

7. Kumar A, Nair AG, Reddy AV, Garg AN, et. al. Bhasmas: Unique ayurvedic metallic-herbal preparations, chemical characterization. Biol Trace Elem Res. 2006; 109:231-54. https://doi.org/10.1385/ BTER:109:3:231

8. Srilakshmi D, Shalini TV, Smitha J, et. al. Therapeutic potentials of sudh varga Rasa Dravya vis -A vis Calcium copmpounds a Review. IRJP. 2012; 3(10).

9. Seth A, Maurya SK, Srivastava A. Formulation development, characterization and estimation of acid neutralization capacity of shankha bhasma tablets for the treatment of dyspepsia. Int J Pharm Pharm Sci. 2014; 6(2):467-9.

10. Pal D, Sahu CK, Haldar A. Bhasma: The ancient Indian nanomedicine. J Adv Pharm Technol Res. 2014; 5:4. https://doi.org/10.4103/2231-4040.126980. PMid:24696811. PMCid:PMC3960793

11. Sadeghi M, Husseini MH. A novel method for the synthesis of $\mathrm{CaO}$ nanoparticle for the decomposition of sulfurous pollutant. J Appl Chem Res. 2013; 7:3949. 
12. Butt AR, Ejaz SJ, Baron C, Ikram M, Ali S, et. al. $\mathrm{CaO}$ nanoparticles as a potential drug delivery agent for biomedical applications. Dig J Nanomater. Biostruc10. 2015:799-809. https://doi.org/10.3390/ su11113196

13. Alavi MA, Morsal A. Ultrasonic-assisted synthesis of $\mathrm{Ca}(\mathrm{OH})_{2}$ and $\mathrm{CaO}$ nanostructures. J Exp Nano Sci. 2010:93-105. https://doi.org/10.1080/174580809 03305616

14. Khan MD, Ahn JW, Nam G. Environmental benign synthesis,characterization and mechanism studies of green calcium hydroxide nano-plates derived from waste oyster shells. JEnviron Manag. 2018;223:947-51. https://doi.org/10.1016/j.jenvman.2018.07.011. PMid:30007890

15. Praikaew W, Kiatkittipong W, Kiatkittipong $\mathrm{K}$, Laosiripojana N, Viriya-empikul N, Boonyasuwat S, et. al. Synthesis of glycerol carbonate from dimethyl carbonate and glycerol using $\mathrm{CaO}$ derived from eggshells. MATEC Web of Conferences; 2018. https://doi.org/10.1051/matecconf/201819203045

16. Rasheed SP, Shivashankar M. Synthesis and characterization of Shanku bhasma-an anti-ulcer herbomineral formulation. IOP Conf Ser: Mater Sci Eng. 2017. https://doi.org/10.1088/1757-899X/ 263/2/022026
17. Liu T, Zhu Y, Zhang X, Zhang T, Zhang T, Li X. Synthesis and characterization of calcium hydroxide nanoparticles by hydrogen plasma-metal reaction method. Mater Lett. 2010; 64:2575-7. https:/doi. org/10.1016/j.matlet.2010.08.050

18. Roy A, Bhattacharya J. Microwave assisted synthesis of $\mathrm{CaO}$ nanoparticles and use in waste water treatment. Nano Technol. 2011; 3:565-8.

19. Yang Y, Wang XH, Sun CK, Li LT. Structural and optical properties of $\mathrm{ZnO}$ nanoparticles synthesized at different $\mathrm{pH}$ Values. Journal of Applied Physics. 2009; 105. https://doi.org/10.1063/1.3121202

20. Zhiwei P, Guozhang D, Peng C, Qinglin Z, Qiang W, Bingsuo. Synthesis, characterization and optical properties of star-like $\mathrm{ZnO}$ nanostructures. Mater Lett. 2010; 64:890. https://doi.org/10.1016/j.matlet. 2010.01.029

21. Singh RK, Kumar S, Kumar A, Kumar S, Kar M, Tripathi S. Physical properties of an Indian Ayurvedic medicine (Shankh Bhasma) as nanomaterials for its application. Indian J Tradit Knowl. 2019; 18(1):17883.

22. Chivhane S, Savrikar S. Study of physico-chemical properties and antimicrobialactivity of shukti marit haratal bhasma invitro. Journal of Pharmaceutical Research. 2017; 6(2). 